Ryszarda BULAS

(Lublin, KUL)

\title{
GRZEGORZ WIELKI W ANGLOSASKIEJ BRYTANII I CELTYCKIEJ IRLANDII
}

Postać papieża Grzegorza Wielkiego, a także jego piśmiennictwo, osiągnęły wielką popularność w Europie Zachodniej wczesnego średniowiecza. Jako duszpasterz i mistrz życia wewnętrznego był popularny w merowińskiej Galii, wizygockiej Hiszpanii, a przede wszystkim w anglosaskiej Brytanii i celtyckiej Irlandii ${ }^{1}$. Teksty Grzegorza były chętnie czytane nie tylko przez ludzi wykształconych, ale także przez szerokie rzesze, dlatego że „chętniej stosował exempla niż tezy doktrynalne" ${ }^{\prime 2}$. Za wiedzę teologiczną, która często przewyższała wiedzę wielu ówczesnych uczonych, obdarzony był głębokim szacunkiem ${ }^{3}$.

Postać i pisma Grzegorza Wielkiego odegrały historyczną i duchową rolę w dziejach Wysp Brytyjskich. Ze względu na ilość przetrwałych do naszych czasów dokumentów, latwiej uchwycić nici łączące słynnego papieża $z$ chrześcijańską, anglosaską Brytanią niż Irlandią. Na podstawie skąpych przekazów możemy jednak choćby naszkicować skalę wpływów, jakie Grzegorz wywarł w Irlandii, a także w środowisku irlandzkich klasztorów, powstałych w merowińskiej Galii.

W 597 roku Grzegorz Wielki wysłał do Brytanii, do Canterbury w księstwie Kent, misję, na czele której stał św. Augustyn, mnich klasztoru św. Andrzeja

${ }^{1}$ O recepcji pism Grzegorza i jego wpływach w Galii i Hiszpanii, zob. F.W. Kellett, Pope Gregory the Great and his relations with Gaul, Cambridge 1889, cyt. za: J.F. Kenney, The Sources of the Early History of Ireland. An Introduction and Guide, New York 1929, 776; H. Ashworth, Gregorian Elements in some Early Gallian Service Books, „Traditio” 13 (1957) 431-443; P. Riché, Edukacja $i$ kultura w Europie Zachodniej (V-VIII wiek), tłum. M. Radożycka-Paoletti, Warszawa 1995, 365nn; M.C. Díaz y Díaz, Literary Aspects of the Visigothic Liturgy, w: E. James (ed.), Visigothic Spain: new Approches, Oxford 1980, 61-76; P.D. King, King Chingasvind and the first territorial Law-code of the Visigothic Kingdom, w: E. James (ed.), Visogothic Spain, 131-158; R. Collins, Mérida and Toledo: 550-585, w: James (ed.), Visigothic Spain, 189-222; o związkach Grzegorza $z$ Leandrem, biskupem Sewilli oraz o korespondencji miedzy nimi, zob. R.A. Markus, Grzegorz Wielki, tłum. P. Nehring, Warszawa 2003, 22-24, 196-199.

${ }^{2}$ Riché, Edukacja i kultura, s. 492.

${ }^{3}$ Por. Riché, Edukacja i kultura, s. 365. Na temat wykształcenia Grzegorza, jego pisarstwa i stosunku do kultury klasycznej oraz jego działalności na polu kształcenia kleru, zob. tamże, s. 152$168,180-187$. 
w Rzymie założonego przez samego Grzegorza ${ }^{4}$. Do dziś historycy dyskutują, co było faktycznym celem tej misji. Wydaje się, że łączyła w sobie kilka zamierzeń papieża. Chodzilo z jednej strony o zażegnanie wewnętrznych walk religijnych wśród Sasów i Anglów, a z drugiej pragnienie Rzymu przeprowadzenia ewangelizacji niegdyś chrześcijańskiej Brytanii, zniszczonej najazdami pogańskich Germanów; szczególnic chodziło o teren południowy. Misja ta była także alternatywą dla ekspansji celtyckiego Kościoła, który od północy prowadził swoją działalność ewangelizacyjną ${ }^{5}$. Misja Augustyna nie skończyła się wielkim sukce$\mathrm{sem}^{6}$. Niewątpliwą jednak zasługą Grzegorza było to, że ustanowił „nowy model pracy misyjnej”, który nie byl „ograniczony wyłącznie do ziem Cesarstwa Rzymskiego, jako naturalnego środowiska dla chrześcijaństwa, ale rozciągał się -

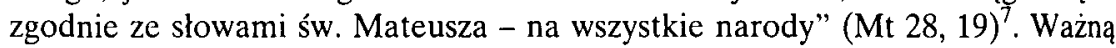
cechą tego modelu było też sugerowane przez Grzegorza podejście do pogan i pogańskich ośrodków kultu, które radzil raczej adaptować niż burzyć. O poganach mówił, że zostali powołani, że są „miejscem” działania miłosierdzia Bożego $^{8}$. Doradzał też pobłażliwość wobec niektórych obyczajów anglosaskich, jeśli nie stoją w sprzeczności $\mathrm{z}$ wiarą chrześcijańską i z doktryną Kościoła; zalecal nawet wykorzystywanie pogańskich świątyń, nakazując niszczyć tylko posagi. Taki model ewangelizacji miał sprzyjać pozyskiwaniu dla wiary nowych wyznawców ${ }^{9}$. Skierowal do nowo nawróconego króla Anglów Ethelberta prośbę, by starał się szerzyć wiarę chrześcijańską wśród swoich pogańskich poddanych oraz porównywał go do Konstantyna Wielkiego. Ten niekwestionowany model ewangelizacji zakorzenił się na długo jako wzór także w chrystianizacji Franków oraz w rozwiązywaniu konfliktów chrześcijańsko-żydowskich w Hiszpaniii ${ }^{10}$.

${ }^{4}$ Na temat tej misji por. S. Gregorii Magni, Epistulae VIII 29, XI 36, XI 56, CCL 140A, 550-553, 925-929, 961-962, ich przekład zob. A. Bober, Anglia, Szkocja, Irlandia. Teksty źródlowe do historii Kościoła i patrystyki I-IX, Lublin 1991, 25-27; Beda, HE II 1, ed. B. Colgrave - R.A.B. Mynors, Bede's Ecclesiastical History of the English People, Oxford 1979; R. Meens, A Background to Augustine's Mission to Anglo-Saxon England, „Anglo-Saxon England” 23 (1994) 5-17; I. Wood, The Mission of Augustine of Canterbury to the English, "Speculum” 69 (1994) 1-17; B. Colgrave, The earliest Life of Gregory the Great, Kansas 1968, 10; H. Chadwick, Gregory the Great and the mission to the Anglo-Saxons, w: Gregorio Magno e il suo tempo, I, Rome 1991, 199-212; W. Lipoński, Narodziny cywilizacji Wysp Brytyjskich, Poznań 2001, 162-164.

5 Por. J.T. McNeill, Irish Saints and English Kings, w: tenże, The Celtic Churches. A History A.D. 200-1200, Chicago - London 1974, 102-119.

${ }^{6}$ R.A. Markus (Grzegorz Wielki, s. 222) twierdzi, że „tym, którzy przybywali z irlandzkiego Wschodu, udało się głębiej zakorzenić chrześcijaństwo w mieszkańcach Northumbrii, niż Augustynowi na poludniu wyspy". Natomiast J.T. McNeill (The Celtic Churches. A History A.D. 2001200, Londyn 1974, 118) pisze, że misja Augustyna była mniej intensywna od irlandzkiej.

${ }^{7}$ Markus, Grzegorz Wielki, s. 222.

8 Por. Moralia IX 9, 10; XXVII 11, 19-21; XXVIII 6, 15; XXIX 25, 50.

${ }^{9}$ Por. Beda, HE I 23; Lipoński, Narodziny cywilizacji Wysp Brytyjskich, s. 185, 232.

${ }^{10}$ Por. Episulae XI 37, CCL 140A, 929-932; Markus, Grzegorz Wielki, s. 100-102 (Chrzescijanie i poganie), 95-100 (Chrześcijanie i Żydzi). 
Wobec historycznej roli, jaką odegrał Grzegorz w anglosaskiej Brytanii, nie dziwi jego wpływ na tamtejszą literaturę, liturgię, monastycyzm i sztukę ${ }^{11}$. Od czasów Grzegorza „Kościól począł rozumieć znaczenie pozawerbalnych sposobów upowszechniania wiary" "2. Zdaniem wielu, zainteresowania artystyczne Grzegorza oraz przekonanie, iż sztuka może być ,wizualną rekolekcją”, miały wpływ na religijną sztukę Brytanii; dziçki niemu anglosaska Brytania poznała także sztukę ikon ${ }^{13}$.

Anglosasi nazywali Grzegorza ojcem i pedagogiem ${ }^{14}$. Szczególnie popularny był w VII i VIII wieku, w którym to czasie powstały też dwie jego biografic: Bedy Czcigodnego i anonimowego mnicha $z$ klasztoru w Whitby. W VII wieku pod wpływem Grzegorza znajdował się Aldhelm oraz kronikarze i pisarze tego czasu $^{15}$. Wówczas też powstał Żywot Grzegorza nieznanego autora $\mathrm{z}$ Whitby, zawierający liczne historie o Grzegorzu ${ }^{16}$. Żywotu tego nie znał jeszcze Beda pisząc swoją Historię narodu angielskiego, gdzie sam zamieścił biograficzny szkic życia Grzegorza (HE, II 1). Tworząc go oparł się na kilku źródlach: na pismach samego Grzegorza (Komentarz do Księgi Hioba, Moralia, Prolog do Dialogów), na jego listach do Leandra, biskupa Sewilli oraz na Liber Pontificalis $^{17}$. W Whitby, York i Canterbury powstały ołtarze dedykowane Grzego-

${ }^{11}$ O wplywie Sakramentarza Grzegorza (Gregorianum), który św. Augustyn miał przywieźć ze sobą do Canterbury, na pisarzy anglosaskich (m.in Egberta z Yorku i Alkuina) zob. H. Ashworth, The Liturgical Prayers of St Gregory the Great, "Traditio” 15 (1953) 106-153; J. Abercrombie, Alcuin and the Test of the Gregorianum: Notes on Combrai MS. No. 164, "Archiv für Liturgiewissenschaft" 3 (1953) 99-103; H.M. Mannister, Liturgical Fragment, JTS 9 (1908) 398; tenże, Fragments of an Anglo-Saxon Sacramentary. JTS 12 (1911) 451; P. Meyvaert, Bede's text of the Libellus Responsionum of Gregory the Great to Augustine of Canterbury, w: England before the Conquest. Studies in primary sources presented to Dorothy Whitelock, Cambridge 1971, 15-33.

${ }^{12}$ Lipoński, Narodziny cywilizacji, s. 246.

${ }^{13}$ Wydaje się, że to on jest odpowiedzialny za pojawienie się pierwszych ikon wśród Anglosasów, por. M. Krasnodębska·D'Aughton, Ikony w sztuce rękopisów irlandzkich i anglosaskich (VII-IX wiek), RH 51 (2003) z. 4, 275; P. Meyvaert, Bede and the Church Paintings at WearmouthJarrow, ,Anglo-Saxon England" 8 (1979) 63-77; P. Meyvaert, Bede and Gregory the Great, w: M. Lapidge (ed.), Bede and his World: Jarrow Lecture 1958-1993, I, Cambridge 1994, 103-122; Joannes Diaconus, Vita Gregorii Magni IV 83-84, PL 75, 229-231; E. Kitzinger, The Cult of Images in the Age before Iconoclasm, w: W.E. Kleinbauer (ed.), The Art of Byzantium and the Medieval West: selected Studies, Bloomington - London 1967, 85-150; H.L. Kessler, Pictorial Narrative and Church Mission in Sixth-Century Gaul, w: H.L. Kessler - M. Shreve Simpson (eds.), Pictorial Narrative in Antiquity and the Middle Ages. Studies in the History of Art, t. 16, Washington 1983, $75 n n$.: C. Chazelle, Pictures, Books and the Illiterate: Pope Gregory I's Letters to Serenus of Marseilles, „Word and Image" 6 (1990) 139-153; H. Belting, Likeness and Presence. A History of the Image before the Era of Art, Chicago - London 1994, 9.

${ }_{14}$ Por. Riché, Edukacja i kultura, s. 398

15 Por. P. Meyvaert, Bede and Gregory the Great, ,Jarrow Lecture” 1964, 1-5.

${ }^{16}$ Por. B. Colgrave (ed.), The Earliest Life of Gregory the Great. Lawrence - Kansas 1967;

Riché. Edukacja i kultura, s. 480.

17 Por. Beda, HE II 1; Markus, Griegorz Wielki, s. 14. 
rzowi, a zbiór kanonów (nr 17) z 747 roku ustanawia święto Grzegorza na 12 marca $^{18}$.

W Irlandii wczesnochrześcijańskiej postać Grzegorza należała do grupy najczęściej czytanych i najbardzicj znanych autorów w okresic od VII do XII wieku. Powszechnic czytano przede wszystkim literaturę dotyczącą monastycyzmu wschodniego: żywoty mnichów egipskich Jana Kasjana, laciński Żywot św. Antoniego, Żywot św. Marcina Sulpicjusza Sewera i Institutiones Kasjodora. Do grupy najczęściej czytanych pisarzy nalcżał Grzegorz Wielki, prócz nicgo, z autorów wczcśniejszych: Orygenes, Hieronim, Ambroży, Euzebiusz, Teodor z Mopsuestii, Grzegorz z Nazjanzu i Grzegorz z Nyssy, Auzoniusz, Seduliusz Szkot, z późniejszych zaś Gildas, Fortunat i Izydor z Sewilli ${ }^{19}$.

Związki Grzegorza Wielkiego z wczesnochrześcijańską Irlandią należy rozważać w kontekście trzech jego dzieł: Komentarza do księgi Hioba, Księgi reguty pasterskiej i przypisywanych mu hymnów. Ze wszystkich dzieł Grzegorza żadne nie było tak poczytne w Irlandii, jak jego Komentarz do Księgi $H i o b a^{20}$. Około stu lat po napisaniu tego dziela powstał w Irlandii olbrzymi jego skrót: Egloga de Morabilibus Job ${ }^{21}$. Jego autorem jest jeden z najbardziej znanych egzegetów irlandzkich tego czasu - Laidcen (Laid-cend lub Lathcen), prawdopodobnie mnich z klasztoru w Clonfert-Molua (Cluain Ferta Molua), który żyl w VII wieku, a nazywany był Laidcenem Mądrym, synem Báeth Bannach $^{22}$. Skrót Laidcena przetrwał w kilku manuskryptach, m.in. z Leningradu (koniec VIII wieku), Laon (VIII-IX wiek) i Karlsruhe (IX wiek); pod-

${ }^{18}$ Por. Bede's Ecclesiastical History II 1, przypis 1.

19 Por. Kenney, The Sources, s. 297; M. McNamara, The Irish Tradition of Biblical Exegesis A.D. 550-800, w: Iohannes Scottus Eriugena. The Bible and Hermeneutics, Leuven 1996, 25-54. Na temat wpływów wykazanych w Collectio Canonum Hibernensis zob. Kenney, The Sources, s. $247 \mathrm{nn}$.

${ }^{20} \mathrm{Na}$ temat tego komentarza zob. m.in. R. Gillet, Introduction, SCh 32, 9-113; P. Aubin, Intériorité et extériorité dans le Moralia in Job de Saint Grégoire le Grand, RSR 62 (1974) 117-166; J. Fontaine, Augustine, Grégoire et Isidore: esquisse d'une recherche sur le style des Moralia in Job, w: Grégoire le Grand, eds. J. Fontaine - R. Gillet - S. Pellistrandi, Paris 1986, 499-509; P. Meyvaert, Uncovering a lost work of Gregory the Great: Fragments of the early Commentary on Job, ,Traditio" 50 (1995) 55-74.

${ }^{21}$ Moralia były popularne nie tylko w Irlandii, ale także w VII-wiecznej Hiszpanii. Tajo z Saragossy udał się nawet po to dzielo w 642 roku do Rzymu, do scrinium (kancelarii) papieskiej, por. Riché, Edukacja i kultura, s. 363; R. Wasselynck, Les compilations des „Moralia in Job" du VII au XII siècle, RTAM 29 (1962) 11-14. Krótką charakterystykę scrinium za czasów Grzegorza Wielkiego podaje Markus, Grzegorz Wielki, s. 15, 28.

${ }^{22}$ Por. K. Hughes, Evidence for Contacts between the Churches of the Irish and English from the Synod of Whitby to the Viking Age, w: taz, Church and Society in Ireland A.D. 400-1200, London 1987, XVI 64, przyp. 1; K. Hughes, Irish Monks and Learning, w: taż, Church and Society, XII 66; obszerną charakterystykę postaci i twórczości Laidcena dokonuje P. Grosjean: Sur quelques exégètes irlandais du VII siècle, „Sacris Erudiri” 7 (1955) 92-96. Martyrologium Oengusso $(35,42-3)$, ułożone na początku IX wieku, przy dacie 12 stycznia posiada dopisek: „Laidcenn syn Baeth'a bannach, cuda Chrystusa interpretowal”, zob. Kenney, The Sources, s. 278; Riché, Edukacja i kultura, s. 331, przyp. 2053. 
pisane są: Egloga quam scripsit Lathcen filius Baith de Moralibus Job quas Gregorius fecit ${ }^{23}$. Pierwszy opublikował fragment tego dzieła Mario Esposito, który oparł się na manuskrypcie z Karlsruhe ${ }^{24}$. Ostatnie krytyczne wydanie dziela Laidcena znajdziemy w Corpus Christianorum ${ }^{25}$.

Irlandia spotkała się z Grzegorzem Wielkim także na polu tworzenia dyscypliny monastycznej. Jeszcze w VI wieku „świat nie uważał żadnej reguły monastycznej za akt normatywny - jak pisze Markus - w mniszej wspólnocie rządziło prawo jej opata, a nie jakiś szczególny dokument" ${ }^{, 26}$. Natomiast w VII wieku zyskiwała popularność koncepcja spisanej Reguły. W Irlandii dominowała Reguła św. Kolumbana, który w końcu VI wieku znalazł się w Galii, zakładając tam klasztory wedle swej reguły ${ }^{27}$. Dowodem zainteresowań Kolumbana problemem jednolitej reguły klasztornej jest jego korespondencja z Grzegorzem. Kolumban w swym liście do tegoż papieża, pisanym ok. 600 roku informuje, że ,pewien Finnian konsultował się z Gildasem”, VI-wiccznym pisarzem anglosaskim, którego autorytet w Irlandii był wielki, na temat dyscypliny monastycznej ${ }^{28}$. Wiemy też, że podczas swego pobytu w Burgundii, Kolumban sprowadzil dla siebie do Luxeuil Liber Regulae pastoralis Grzegorza ${ }^{29}$. W 594 r. Grzegorz posłał kopię Liber Regulae pastoralis do „kaplana Kolumbana", o czym pisze w swoim liście Kolumba ${ }^{30}$. W tym samym liście Kolumban zwrócił się z prośbą do Grzegorza o przesłanic mu swoich Homilii do Księgi Ezechiela oraz dalszego ciągu komentarza do Pieśni nad Pieśniami, wypytując go jednocześnie o znaczenie proroctw Zachariasza ${ }^{31}$.

Liber Regulae pastoralis musiała być bliska mentalności i koncepcji monastycznej Irlandczyków. Grzegorz pisząc ją oparł się na traktacie $O$ życiu kontemplacyjnym Juliana Pomeriusza, mieszkańca Arles zamieszkałego w Afryce, na

${ }^{23}$ Por. B. Bischoff, Wendepunkte in der Geschichte der lateinischen Exegese im Frühmittelalter, „Sacris Erudiri” 6 (1954) 234; Grosjean, Les exégètes, s. 94., A Staerk, Les manuscripts latins du $V^{*}$ au XIII siècle conserves à bibliothèque impériale de Saint-Pétersbourg, t. 1, Saint-Pétersbourg 1910, 40; L. Gougaud, Le témoignage des manuscripts sur l'oeuvre littéraire du moine Lathcen, „Revue Celtique” 30 (1909) 37-43.

24 Por, M. Mario Esposito, The Latin Writers of Mediaeval Ireland, „Hermathena” 14 (1907) 528 i 15 (1909) 358, oraz w: tenże, Latin Learning in Mediaeval Ireland, ed. M. Lapidge, London 1988, I, 519-529; II, 352-364.

${ }^{25}$ Lathcen, Egloga quam scripsit Lathcen filius Baith de Moralibus Job quas Gregorius fecit, CCL 145, Turnholti 1969.

${ }^{26}$ Markus, Grzegorz Wielki, s. 88.

27 Por. Regula monachorum - Regula coenobialis, PL 80, 209-224, thum. E. ZakrzewskaGębka - S. Kalinkowski - A. Mikołajczak, PSP 60, 134-150; E. Derdziuk, Mnisi iroszkoccy. Św. Kolumba Mtodszy - ewangelizacja Europy, Lublin 1997.

${ }^{28}$ Por. Epistula 1, 7, PSP 60, 82, oraz przypis 206; Kenney, The Sources, s. 177.

${ }^{29}$ Por. Kenney, The Sources, s. 177; jej tekst zob. SCh 381-382, jej nowy polski przekład: E. Szwarcenberg-Czerny, Krakow 2003, ŹM 29; Markus, Grzegorz Wielki, s. 29-30, 31-42.

${ }^{30}$ Por. Epistula 1, 9, PL 80, 263, PSP 60, 83; Riché, Edukacja i kultura, s. 337, przypis 2095.

31 Por. Episula 1, 9; o homiliach Grzegorza zob. Markus, Grzegorz Wielki, s. 28-30. 
idealach monastycznych Jana Kasjana, a także na regule Benedykta ${ }^{32}$. Grzegorz, podobnie jak Irlandczycy, dążył do połączenia kontemplacji z działaniem, jego zaś koncepcja „różnorodności w jedności” „nić przewodnia jego duszpasterskich zasad", była bliska Irlandczykom. Pisma Jana Kasjana należą do najczęściej czytanych w Irlandii, a klasztory iryjskie o regule kolumbańskiej na terenie Galii, prócz kilku wyjątków, przyjęły w VII wieku regułę benedyktyńską ${ }^{33}$.

$\mathrm{Z}$ listu Kolumbana do papieża wiemy, jak żywo zaangażował się on w tzw. kontrowersję paschalną ${ }^{34}$. Kolumban należał do frakcji broniącej celtyckiej wersji święcenia Wielkanocy. Mimo ze wiedza o obliczaniu dnia Wielkanocy była mu znana, bo zaznacza o tym w swym liście do Grzegorza ${ }^{35}$, to wyrazal zdziwienie, że papież nie „wytępił" już dawno tego niewłaściwego obyczaju, za jaki uważal lacińską metodę obliczania daty Wielkanocy. Papież odpowiedział Kolumbanowi poprzez swego posłannika, że to, co zostało utwierdzone przez dhugotrwałą praktykę, nie może być zmienione ${ }^{36}$. Kolumban został przy swoim zdaniu, ale na trzy listy wysłane do papieża nie uzyskał żadnej odpowiedzi. Trudności w komunikacji z papieżem przypisał Szatanowi, który nie chciał dopuścić do tego, by jego listy dotarły do papież ${ }^{37}$. W Irlandii istniała także frakcja opowiadająca się za rzymską opcją, do której należał opat klasztoru w Durrow, Cummian, na którego wpływ miały, jak wykazano, Moralia Grzegorza ${ }^{38}$.

Mimo tych rozbieżności Kolumban włączył się w walkę $\mathrm{z}$ arianizmem w Longobardii. Tamtejszy dwór ,,przekonał niedawnego imigranta, irlandzkiego mnicha Kolumbana, obecnie przebywającego w Bobbio, do podjęcia próby zjednoczenia Kościołów Italii pod władzą papieża i królów longobardzkich" ${ }^{39}$. Kolumban i jego mnisi „usiłowali doprowadzić do tego pojednania około $613 \mathrm{r}$., ale na ostateczny sukces tego procesu trzeba byla czekać do końca wieku"40.

${ }^{32}$ R.A. Markus (Grzegorz Wielki, s. 33-34, 29, 87-88) mówi o glębokim podobieństwie koncepcji Grzegorza do pomysłów Jan Kasjana i Juliana, oraz o jego stosunku do św. Benedykta.

${ }^{33}$ Por. Riché, Edukacja i kultura, s. 346-347 (Reguła kolumbańska rozpowszechniona przez Irów).

${ }^{34}$ Por. Epistula 1, 3-4; na temat kontrowersji paschalnej w Irlandii zob. K. Hughes, The Celtic Church and Papacy, w: taż, Church and Society, XV, 10; K. Hughes, Evidence for Contacts, w: taż, Church and Society, XVI, 64; P. Grosjean, Recherches sur les débuts de la controverse pascale chez les Celtes, AnBol 64 (1946) 200-244.

35 Por. Epistula 1, 3; owym uczonym dokonującym obliczeń byl prawdopodobnie Monino Mocano ( $\dagger 610$ ), który miał podjąć próbę wprowadzenia do Irlandii obliczeń Dionizego, zob. Grosjean, Rechereches sur les débutes, s. 231; Riché, Edukacja i kulura, s. 323.

${ }^{36}$ Por. Epistula 2, 5.

37 Por. Epistula 3, 2.

38 Por. M. Mario Esposito, Notes on Latin Learning and Literature in Mediaeval Ireland, „Hermathena” 22 (1932) 234 oraz Latin Learning in Mediaeval Ireland, IV, 234; J.E.L. Oultan, The Epistle of Cummian „De controversia paschali”, StPatr 1 (1957) 128-133.

39 Markus, Grzegorz Wielki, s. 166.

40 Tamże; por. P. Delogu, Il regno longobardo, w: Storia d'Italia, I: Longobardi e Bizantini, Torino 1980, 44; Paweł Diakon, Historia Longobardów, tłum. i oprac. I. Lewandowski, Warszawa 1995, VI, 14. 
J.K. Kenney pisze, że Grzegorz został zaadaptowany w Irlandii dzięki swym hymnom tygodnia ${ }^{41}$. Wprowadzenie do X lub XI wieku kopii słynnego hymnu Altus Prosator Kolumby Starszego (Colum Cilla) ${ }^{42}$, sugeruje, ze hymn ten był posłany do Grzegorza jako podziękowanie za jego prezent - krzyż zwany "The Great Gem” i za „Hymny tygodnia” (Hebdomada hymnorum $)^{43}$. Inny hymn przypisywany Kolumbie (choć faktycznie późniejszy) „In te Christe", mial być odpowiedzią na krytyczną opinię Grzegorza pod adresem Altus Prosator, który zarzucal autorowi, że w hymnie modlitwa do Trójcy Świętej jest tylko pośrednia ${ }^{44}$.

Niewątpliwie, $z$ racji korespondencji, największe kontakty z Grzegorzem miał Kolumban Młodszy, którego pisarstwo wykazuje wpływy pism papieża ${ }^{45}$. W Bobbio, klasztorze założonym przez Kolumbana, powstało za czasów opata Bobolenusa (641-654) skryptorium ${ }^{46}$. Biblioteka posiadała wówczas dzieła wielu autorów, m.in. Grzegorza Wielkiego; wiemy też, że ok. 650 r. w skryptorium tym przepisana została III księga jego Dialogó $w^{47}$. Wykazano, że piśmiennictwo Grzegorza, szczególnie jego Dialogi (II i IV) miały znaczny wpływ także na twórczość Adomnana († 704), opata klasztoru na wyspie Iona ${ }^{48}$.

Osobną grupę tworzą dzieła iryjskie lub pod wpływami iryjskimi, w których również stwierdzono wpływ piśmiennictwa Grzegorza. Widać to wyraźnie w następujących pismach:

a. Book of Armagh w swej części liturgicznej ma liczne odniesienia i aluzje do życia św. Grzegorza. Pisane są ręką Fer-domnacha, którego żywot Annaty Ulsterskie umieszczają pod datami: $808,846^{49}$.

${ }^{41}$ Por. The Sources, s. 715.

42 Por. C. Blume, Analecta hymnica 51, Leipzig 1908, 282-283; S. Longosz, Hymny św. Hilarego i Kolumby, w: Bóg Ojciec i przełom wieków w myśli patrystycznej, SACh 15, Warszawa 2001, 271-292; E. Hull, Hymns-Irish Christian, w: Encyclopedia of Religion and Ethics, VII, New York 1955, 25-28; F.C. Burkitt, On two early irish hymns, JTS 3 (1902) 95-96; B. Muir, Two latin hymns by Colum Cille, „Revue de Moyen Âge Latin” 39 (1983) 210.

${ }^{43}$ Por. Hymni a beato Gregorio papa conscripti, PL 78, 849-852; Kenney, The Sources, s. 264265; Longosz, Hymny św. Hilarego i Kolumby, s. 283-286.

44 J.K. Kenney (The Sources, s. 264) w swoim komentarzu thumaczy Kolumbę przypominając, że teologia wczesnośredniowieczna osadzona była w wiedzy na temat nadnaturalnego swiata, wywodziła się bowiem z neoplatońskiej Hierarchii Niebiańskiej Pseudo-Dionizego Areopagity oraz z żydowskiego apokryfu Ksiega Henocha.

${ }^{45}$ Prócz Grzegorza wpływ na pisarstwo Kolumbana mieli następujący autorzy: Euzebiusz, Hieronim, Seduliusz, Auzoniusz, Drakoncjusz, Gildas, Fortunat, a także Wergiliusz i Horacy, por. Kenney, The Sources, s. 174.

${ }^{46}$ Por. Jonas, Vita S. Columbani 1 15, PSP 60, 200-201.

${ }^{47}$ Biblioteka posiadala także dzieła: Augustyna, Hilarego, Orygenesa i Hieronima, por. Riché, Edukacja i kultura, s. 354-355.

${ }^{48}$ D.A. Boullough, Columba, Adomnan and the Achievement of Iona, „Scottish Historical Review" 44 (1965) 17-33.

${ }^{49}$ Por. Kenney, The Sources, s. 338. 
b. Tekst w Codex Paulinus Wirziburgensis z Würzburga, datowany na IX$\mathrm{X}$ wiek, ma odniesienia do Grzegorza Wielkiego, a także do Pelagiusza, Orygenesa ( $w$ thum. Rufina), Ambrozjastra, Hieronima, Augustyna, Kasjodora i Izydora ${ }^{50}$.

c. Kopia listów św. Pawła autorstwa Marianusa Scottusa, dziś w Codex Vindobonensis 1247 , datowany na rok 1079 . Wiemy, że oryginalny tekst posiadał komentarze do Księgi reguty pasterskiej Grzegorza Wielkiego oraz do Hieronima, Augustyna, Orygenesa, Kasjana, Haimo z Auxerre, Leona, Pelagiusza i Alkuina ${ }^{51}$.

d. Wielki Ewangeliarz Máel-Brigte, pisany w Armagh pod datą 1138, posiada komentarz do Ewangelii oparty na pismach Grzegorza Wielkiego oraz Orygenesa, Hieronima, Cypriana, Euzebiusza i Leona ${ }^{52}$.

e. O pewnych ideowych związkach między Irlandią i Grzegorzem może świadczyć również fakt, że na terenach Galii znane są przypadki, iż mnisi klasztoru galijskiego łączyli zainteresowanie tekstami irlandzkimi i tekstami Grzegorza Wielkiego. W Méobec, w diecezji Bourges, pewien mnich był znany z tego, że znal homilie Grzegorza i literaturę irlandzką, a ok. 678 r. napisał Visio Baronti, tekst w typie literatury wizyjnej, popularnej w Irlandii ${ }^{53}$.

Popularność Grzegorza przetrwała w Irlandii do XII wieku, kiedy to jego postać przybrała legendarny, a nawet fantastyczny wymiar. W Liber Ardmachanus, pochodzącym z XI/XII wieku, będącym kompilacją anegdot o świętych, znajduje się tekst pt. Vita $S$. Gregorii papae oraz Miraculum S. Gregorii papae, w których zaliczono Grzegorza w poczet narodowych świętych Irlandii. Vita informuje, że Grzegorz urodził się w Irlandii jako potomek króla Kerry Conaira, a pochowany został na irlandzkiej wyspie Aran, słynnej z licznych klasztorów ${ }^{54}$.

50 Por. tamze, s. 635-636.

51 Por. tamże, s. 618-619.

52 Por. tamże, s. 648.

${ }^{53}$ Por. Riché, Edukacja i kultura, s. 374, przypis 2357; M. De Laurgardière, L'église de Bourges avant Charlemagne, Paris 1951, 188-198.

${ }_{54}$ Por. P. Grosjean, Catalogus codicum hagiographicorum latinorum. Bibliothecarum dubliniensium, AnBol 46 (1928) 81-148; tenze, Notes d'hagiographie celtique, AnBol 61 (1943) 91-100. W Irlandii znajduje się mały utwór Liber de Gradibus Caeli, który niesłusznie przypisuje się Grzegorzowi wskazując na słownictwo zapożyczone z Moraliów Grzegorza, omówienie tego utworu w: P. Grosjean, tamże, 99-102. 


\section{GREGORY THE GREAT IN ANGLO-SAXON BRITAIN \\ AND CELTIC IRELAND}

(Summary)

The article is the short compendium of the information about Gregory's the Great connections with Anglo-Saxons and Irish, in VII ${ }^{\text {th }}$-XII ${ }^{\text {th }}$ century period. Connections with Britain: Augustine's Mission, Gregory's model of the evangelization, the conception of religious function of the art (visual recollection, icons), the earliest Life of Gregory, (anonymous monk from Whitby, Bede Venerabilis). Connections with Ireland: Laidcen's Egloga de Morabilibus Job, Columban's letters to Gregory, Regula pastoralis, paschal controversy, irish manuscripts $\left(\mathrm{IX}^{\mathrm{th}}-\mathrm{XII}^{\mathrm{th}}\right.$ ) with allusion to Gregory's writings. 